\title{
ON FSUM MODEL AND APPLICATIONS
}

\author{
Dang Huu Chung \\ Institute for Mechanics, VAST, Hanoi, Vietnam
}

\begin{abstract}
In this paper a 3D model (FSUM) on tidal flows with sediment transport and bed morphology process taking into account the temperature-salinity exchange in estuaries and coastal zones is introduced in more detail. The implicit finite difference method based on semi-Lagrange splitting is used. The software is coded with FORTRAN 90/95. The open boundary condition kinds together source/sink terms are well treated so that it can be applied to every computing domain with the complicated geometry. The software is validated and applied for many different cases and shows the ability of application in practice.
\end{abstract}

\section{INTRODUCTION}

The significant achievements in Information Technology enable scientists to develop and improve computing software for effectively solving the problems in engineering, especially in computational fluid dynamics. Within the common context of progress the numerical simulation and prediction on tidal flow, sediment transport and coastal bed morphology become feasible and attract many scientists in the world. Although so far there are quite lots of software for this field, self-development is still necessary and plays an important role. It certainly will bring the permanent and practical benefit for scientific progress of the country while the investment is not too expensive in comparison with available trade software. However, this is not an easy work and it always requires efforts and endurance.

In this paper FSUM model (tidal Flow, SUbstances transport and Morphology) that was developed and applied for study will be presented in detail. The scope of application is the problems of fluid flows in lake, river, estuary and coastal zone with sediment transport, temperature salinity exchange and bed update due to erosion and deposition processes.

\section{GOVERNING EQUATIONS OF FSUM MODEL}

The governing mathematical equations are Reynolds-averaged Navier-Stokes for an incompressible free-surface flow with the non-hydrostatic pressure correction included (Chung, D.H, 2008), together with the transport equations for substances and an equation 
describing the bottom evolution (Chesher,T.J., et al., 1993) as follows:

$$
\begin{aligned}
& \nabla \cdot \vec{V}= 0 \\
& \frac{\partial \vec{V}}{\partial t}+(\nabla \cdot \vec{V}) \vec{V}=-\frac{1}{\rho} \nabla p+\nu^{h} \nabla_{x y}^{2} \vec{V}+\frac{\partial}{\partial z}\left(\nu^{v} \frac{\partial \vec{V}}{\partial z}\right)+\vec{\Omega}+\vec{F} \\
& \quad \frac{\partial s}{\partial t}+\vec{V}_{s} \cdot \nabla s=\varepsilon_{s}^{h} \nabla_{x y}^{2} s+\frac{\partial}{\partial z}\left(\varepsilon_{s}^{v} \frac{\partial s}{\partial z}\right) \\
&\left(1-p_{r}\right) \frac{\partial z_{b}}{\partial t}=\left(\frac{\partial q_{t x}}{\partial x}+\frac{\partial q_{t y}}{\partial y}\right)+\int_{-z_{b}+z_{a}}^{\eta} \frac{\partial c}{\partial t} d z
\end{aligned}
$$

in which $t$ is the time, $x, y, z$ the spatial coordinates, $\vec{V}=(u, v, w)^{T}$ the velocity vector of flow, $\vec{\Omega}=(f v,-f u, 0)^{T}$ the Coriolis acceleration vector, $\vec{F}=(0,0,-g)^{T}, g$ the acceleration of gravity, $\rho$ the water density, $p$ the non-hydrostatic pressure, $\nu^{h}, \nu^{v}$ the horizontal and vertical momentum diffusion coefficients, $\vec{V}_{s}=\left(u, v, w-w_{s}\right)^{T}, w_{s}$ the settling velocity of solid particle, $s$ the temperature, salinity or suspended sand concentration, $\varepsilon_{s}^{h}, \varepsilon_{s}^{v}$ the horizontal and vertical diffusion coefficients for suspended sediment, $z_{b}$ the bed level with the downward positive direction, $q_{t x}, q_{t y}$ the total sediment flux components, $\eta$ the water level, $z_{a}$ the reference level and $p_{r}$ the porosity.

The initial conditions are:

$$
\eta(x, y, t)=\mathrm{const}, \vec{V}(x, y, z, t)=0, s(x, y, z, t)=0, \quad z_{b}(x, y, t)=f_{1}(x, y), t=0
$$

in which $f_{1}(x, y)$ is given by the bathymetry map.

The boundary conditions include:

- Land boundary condition:

$$
V_{n}(x, y, z, t)=0, \quad \forall(x, y, z) \in L, \quad \forall t>0
$$

- Open boundary condition:

$$
\eta(x, y, t)=f_{2}(x, y, t), \quad s(x, y, z, t)=f_{3}(x, y, z, t),(x, y) \in \Gamma, \quad \forall t>0
$$

in which $f_{i}(i=2,3)$ are the given functions or from measurement.

- Boundary conditions on surface (by wind):

$$
\nu^{v} \frac{\partial u}{\partial z}=\frac{\tau_{x}^{w}}{\rho}, \quad \nu^{v} \frac{\partial v}{\partial z}=\frac{\tau_{y}^{w}}{\rho}, \quad \varepsilon_{s}^{v} \frac{\partial s}{\partial z}=\left(w-w_{s}\right) s, \quad z=\eta
$$

in which

$$
\vec{\tau}^{w}=f_{a} \rho_{a}\left|\vec{V}_{w}\right|\left(\vec{V}_{w}-\vec{V}_{\eta}\right), \quad \vec{V}_{\eta}=\vec{V}(x, y, \eta, t), \quad f_{a}=1.4 \cdot 10^{-3}, \quad \rho_{a}=1.25 \mathrm{~kg} / \mathrm{m}^{3}
$$

- Boundary conditions on bottom (by bed friction):

$$
\nu^{v} \frac{\partial u}{\partial z}=\gamma u, \quad \nu^{v} \frac{\partial v}{\partial z}=\gamma v, \quad \varepsilon_{s}^{v} \frac{\partial s}{\partial z}=\left(w-w_{s}\right) s, \quad z=-z_{b},
$$

in which

$$
\gamma=\frac{g}{C^{2}} \sqrt{u^{2}+v^{2}}, \quad C=\frac{1}{n} d^{1 / 6}
$$


$n$ is Manning coefficient and $d$ is the water thickness of layer. The other parameters can be found in some documents such as Chung, D.H (2007), Chung, D.H and Van Rijn, L.C. (2003), Soulsby, R. (1997) and Van Rijn, L.C., (1984).

\section{DISCRETIZATION OF EQUATIONS}

FSUM model is coded with FORTRAN 90/95 and based on the algorithm proposed by Casulli, V. and Stelling, G.S., (1998). By introducing the characteristics:

$$
\frac{d x}{d t}=u, \frac{d y}{d t}=v, \frac{d z}{d t}=w
$$

The momentum equation (2) becomes

$$
\frac{d \vec{V}}{d t}=-g \nabla_{x y} \eta-g \int_{z}^{\eta} \nabla_{x y} \frac{\rho^{\prime}}{\rho_{0}} d z-\nabla q+\nu^{h} \nabla_{x y}^{2} \vec{V}+\frac{\partial}{\partial z}\left(\nu^{v} \frac{\partial \vec{V}}{\partial z}\right)+\vec{\Omega}+\vec{F}
$$

and it is discretized in two steps as follows

First step: Hydrostatic pressure

$$
\begin{gathered}
\tilde{u}_{i+1 / 2, j, k}^{n+1}=F u_{i+1 / 2, j, k}^{n}-(1-\theta) \frac{\Delta t}{\Delta x}\left\{g\left(\eta_{i+1, j}^{n}-\eta_{i, j}^{n}\right)+q_{i+1, j, k}^{n}-q_{i, j, k}^{n}\right\} \\
-(1-\theta) \frac{\Delta t}{\Delta x} g\left(\eta_{i+1, j}^{n+1}-\eta_{i, j}^{n+1}\right)+\nu^{v} \Delta t \frac{\frac{\tilde{u}_{i+1 / 2, j, k+1}^{n+1}-\tilde{u}_{i+1 / 2, j, k}^{n+1}}{\Delta z_{i+1 / 2, j, k+1 / 2}^{n}}-\frac{\tilde{u}_{i+1 / 2, j, k}^{n+1}-\tilde{u}_{i+1 / 2, j, k-1}^{n+1}}{\Delta z_{i+1 / 2, j, k-1 / 2}^{n}}}{\Delta z_{i+1 / 2, j, k}^{n}} \\
\tilde{v}_{i, j+1 / 2, k}^{n+1}=F \tilde{v}_{i, j+1 / 2, k}^{n}-(1-\theta) \frac{\Delta t}{\Delta y}\left\{g\left(\eta_{i, j+1 / 2}^{n}-\eta_{i, j}^{n}\right)+q_{i, j+1 / 2, k}^{n}-q_{i, j, k}^{n}\right\} \\
-(1-\theta) \frac{\Delta t}{\Delta y} g\left(\eta_{i, j+1}^{n+1}-\eta_{i, j}^{n+1}\right)+\nu^{v} \Delta t \frac{\frac{\tilde{v}_{i, j+1 / 2, k+1}^{n+1}-\tilde{v}_{i, j+1 / 2, k}^{n+1}}{\Delta z_{i, j+1 / 2, k+1 / 2}^{n}}-\frac{\tilde{v}_{i, j+1 / 2, k}^{n+1}-\tilde{v}_{i, j+1 / 2, k-1}^{n+1}}{\Delta z_{i, j+1 / 2, k-1 / 2}^{n}}}{\Delta z_{i, j+1 / 2, k}^{n}}
\end{gathered}
$$

in which

$$
\begin{aligned}
& \left.F u_{i+1 / 2, j, k}^{n}=\left\{u_{i+1 / 2, j, k}^{n}+\Delta t \text { (baroclinic }+ \text { coriolis }+ \text { hor.dif }\right)\right\}_{O}^{n} \\
& \left.F v_{i, j+1 / 2, k}^{n}=\left\{v_{i, j+1 / 2, k}^{n}+\Delta t \text { (baroclinic }+ \text { coriolis }+ \text { hor.dif }\right)\right\}_{O}^{n}
\end{aligned}
$$

For hydrostatic pressure Eq.(1) is used to determine $w_{i, j, k+1 / 2}^{n+1}$. Eq.(2) is discretized in the same way for non-hydrostatic case instead. 
The water level in the first step is determined by:

$$
\begin{aligned}
\tilde{\eta}_{i, j}^{n+1}= & \eta_{i, j}^{n}-\theta \frac{\Delta t}{\Delta x}\left(\sum_{k=m}^{M} \Delta z_{i+1 / 2, j, k}^{n} \tilde{u}_{i+1 / 2, j, k}^{n+1}-\sum_{k=m}^{M} \Delta z_{i-1 / 2, j, k}^{n} \tilde{u}_{i-1 / 2, j, k}^{n+1}\right) \\
& -\theta \frac{\Delta t}{\Delta y}\left(\sum_{k=m}^{M} \Delta z_{i, j+1 / 2, k}^{n} \tilde{v}_{i, j+1 / 2, k}^{n+1}-\sum_{k=m}^{M} \Delta z_{i, j-1 / 2, k}^{n} \tilde{v}_{i, j-1 / 2, k}^{n+1}\right) \\
& -(1-\theta) \frac{\Delta t}{\Delta x}\left(\sum_{k=m}^{M} \Delta z_{i+1 / 2, j, k}^{n} \tilde{u}_{i+1 / 2, j, k}^{n}-\sum_{k=m}^{M} \Delta z_{i-1 / 2, j, k}^{n} \tilde{u}_{i-1 / 2, j, k}^{n}\right) \\
& -(1-\theta) \frac{\Delta t}{\Delta y}\left(\sum_{k=m}^{M} \Delta z_{i, j+1 / 2, k}^{n} \tilde{v}_{i, j+1 / 2, k}^{n}-\sum_{k=m}^{M} \Delta z_{i, j-1 / 2, k}^{n} \tilde{v}_{i, j-1 / 2, k}^{n}\right) \\
& +\frac{\Delta t}{\Delta x \Delta y} \sum_{s} q_{s}, \quad 2 \leq i \leq \operatorname{Imx}-1 ; 2 \leq j \leq \mathrm{Jmx}-1
\end{aligned}
$$

By eliminating the velocity components from Eq.(14) and using conjugate gradient method the water level at time step $n+1$ will be obtained, then the velocity components will calculated from Eqs. (12)-(13).

Second step: Non-hydrostatic correction

$$
\begin{array}{r}
u_{i+1 / 2, j, k}^{n+1}=\widetilde{u}_{i+1 / 2, j, k}^{n}-\theta \frac{\Delta t}{\Delta x}\left\{q_{i+1, j, k}^{n+1}-q_{i, j, k}^{n+1}\right\} \\
v_{i, j+1 / 2, k}^{n+1}=\widetilde{v}_{i, j+1 / 2, k}^{n}-\theta \frac{\Delta t}{\Delta y}\left\{q_{i, j+1, k}^{n+1}-q_{i, j, k}^{n+1}\right\} \\
w_{i, j, k+1 / 2}^{n+1}=\widetilde{w}_{i, j, k+1 / 2}^{n+}-\theta \frac{\Delta t}{\Delta z}\left\{q_{i, j, k+1}^{n+1}-q_{i, j, k}^{n+1}\right\} \\
\eta_{i, j}^{n+1}=\widetilde{\eta}_{i, j}^{n+1}+\frac{q_{i, j, M}^{n+1}}{g}
\end{array}
$$

The conjugate gradient method is also used again to solve the equations.

The semi-Lagrange method is also applied to the diffusion equations (3) for temperature, salinity and suspended sediment concentration and the difference equations are as follows:

$$
\begin{array}{r}
l_{k} s_{i, j, k+1}^{n+1}+d_{k} s_{i, j, k}^{n+1}+u_{k} s_{i, j, k-1}^{n+1}=b_{i, j, k} \\
2 \leq i \leq \operatorname{Imx}-1 ; 2 \leq j \leq \operatorname{Jmx}-1 ; \mathrm{m} \leq \mathrm{k} \leq \mathrm{M}
\end{array}
$$

Eqs.(19) are a tri-diagonal system and easy to solve by Thomas algorithm.

Eq.(4) for bed update is solved by second order Lax-Wendroff:

$$
z_{b i, j}^{n+1}=z_{b i, j}^{n}+\left.\Delta t \frac{\partial z_{b}}{\partial t}\right|_{i, j} ^{n}+\left.\frac{\Delta t^{2}}{2} \frac{\partial^{2} z_{b}}{\partial t^{2}}\right|_{i, j} ^{n}+O\left(\Delta t^{2}\right)
$$




\section{MODEL VALIDATION AND APPLICATIONS}

\subsection{Wave propagation over a bar}

This model run is to verify FSUM with the data set from Delta flume experiment at Delft Hydraulics. The purpose of this experiment is to study the spatial evolution of very steep waves propagating over a longshore bar. The sketch of the delta flume is shown in Fig. 1. Its length is $30 \mathrm{~m}$ with the bed slopes of $1 / 20,-1 / 10$ and $1 / 25$, respectively under a still water level of $0.4 \mathrm{~m}$ and reduced to $0.1 \mathrm{~m}$ on the bar. A sinusoidal wave with the amplitude of $1 \mathrm{~cm}$ and a period of $2.02 \mathrm{~s}$ is generated at the left open boundary. The computational domain is covered with a grid $5 \times 1200(\Delta x=\Delta y=0.025 \mathrm{~m})$. The vertical direction is divided into 20 layers $(\Delta z=0.025 \mathrm{~m})$. The time step is $\Delta t=0.025 \mathrm{~s}$ and the simulation time is 45 seconds.

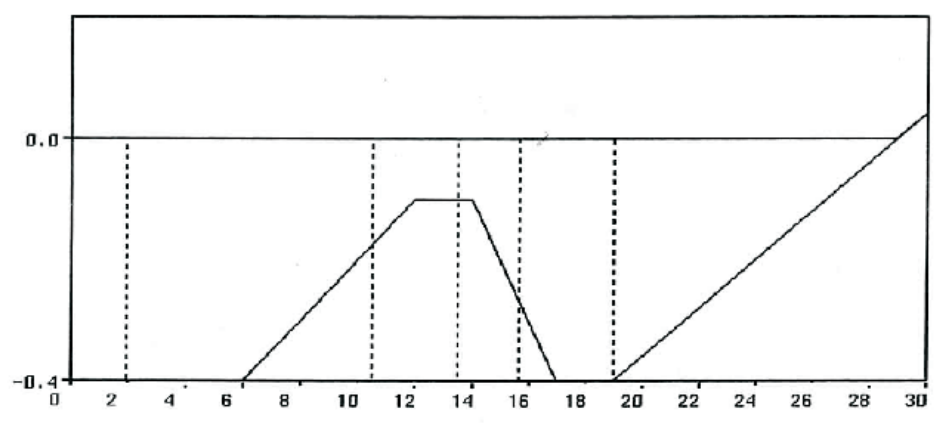

Fig. 1. Delta flume geometry

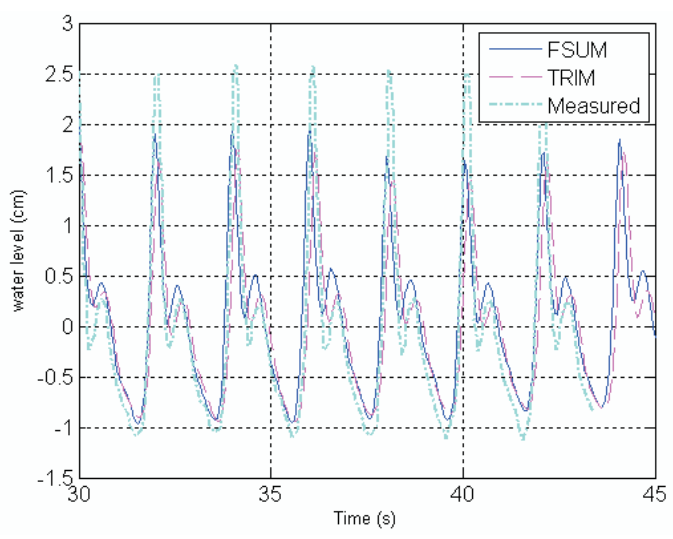

Fig. 2. Water levels at the position of $13.5 \mathrm{~m}$ of Delta flume

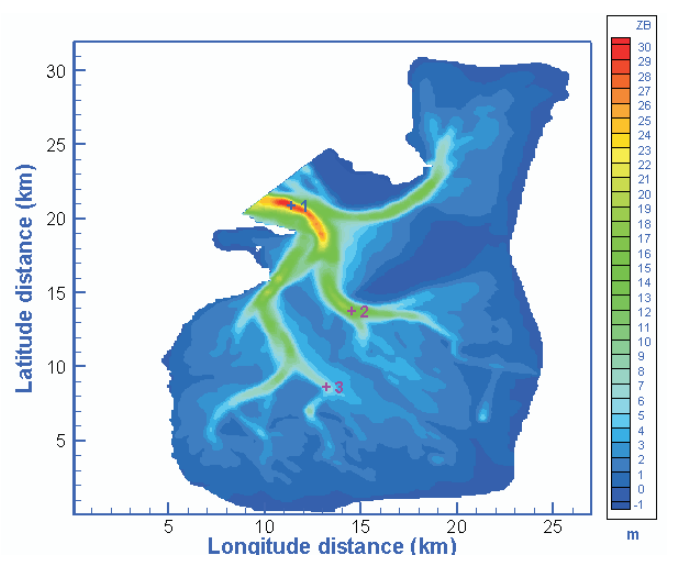

Fig. 3. Bathymetry of Sylt-Romo

The computational result of FSUM is compared with measured data at the location of $13.5 \mathrm{~m}$ and with the result by TRIM model as presented in Fig. 2. It is shown that the results by FSUM and TRIM (a specific setting up) are quit similar and fit well the 
behaviour of measured data although the oscillation amplitude of water level by measurement is about $1 \mathrm{~cm}$ higher.

\subsection{Tidal flow and sediment transport over Sylt-Romo bay}

Short-term simulations of the bottom evolution of the Sylt-Romo tidal bay under the influence of strong wind and tidal water motion for the period from May 23, 1992 to May 30, 1992 are carried out. The period over which sediment transport was simulated is characterized by windy weather with maximum wind speeds of about $17 \mathrm{~m} / \mathrm{s}$ coming from north-west direction. The wave field was also taken into account and supposed to propagate in the same direction of wind with a constant height of $0.5 \mathrm{~m}$. These assumptions were used as an alternative solution for the lack of measured data.

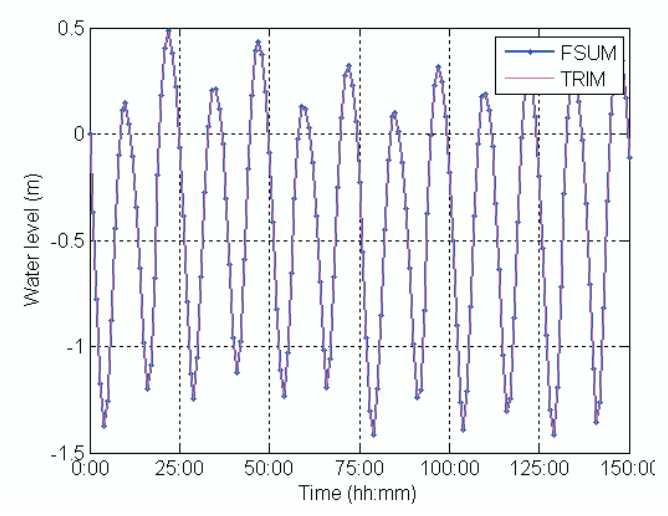

Fig. 4. Water levels versus time at the position 1

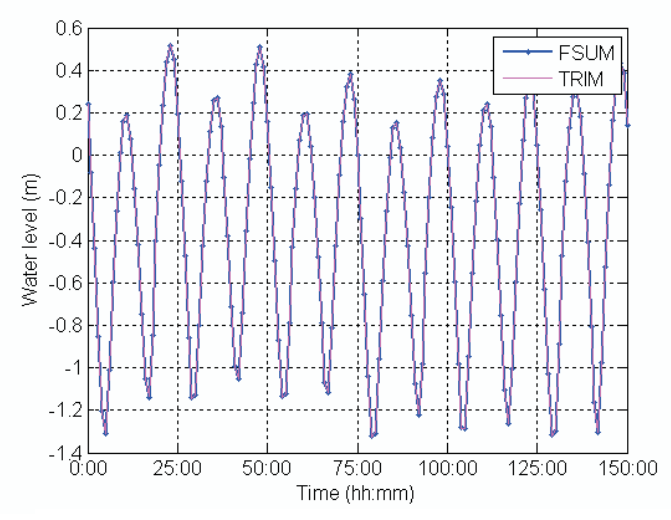

Fig. 5. Water levels versus time at the position 2

The computational domain is covered with a grid $270 \times 320(\Delta x=\Delta y=100 \mathrm{~m})$. The vertical direction is divided into 65 layers $(\Delta z=0.5 \mathrm{~m})$. The time step is $\Delta t=20 \mathrm{~s}$ and the simulation duration is 150 hours. The bathymetry of Sylt-Romo and three positions to compare the computed result with TRIM model (Chung, D.H and Eppel, D., 2003, 2007) are shown in Fig. 3. It can be seen that the whole bay is shallow except the very deep channel. Figures 4-6 present comparisons of water levels versus time with TRIM model at three positions. It is shown that they are much the same. The comparisons of velocities at two depths near bottom and closed to MSL for the position 1 are shown in Figures 7-8. Figures 9-12 are the same comparisons for the positions 2 and 3. From here it can be seen that the velocities by the two models at the deep water (position 1) fit well. There are some discrepancies at the shallow positions. Howver their behaviours are quite similar. Figures 13-15 compare suspended sand concentration versus time and Figures 16-18 are for the total sand transport rates. They also confirm the fitness between two models. The velocity profiles at three positions are compared in Figures 19-21 and it is shown that the discrepancy tend to happen in the upper half of water depth.

\subsection{Tidal flow and sediment transport over Ba Lat coastal zone}

The bathymetry of Ba Lat coastal zone is shown in Fig. 22 together with three positions to compare the computed results. The computation domain is covered by the 
regular grid of $425 \times 250$ cells with the grid size of $120 \mathrm{~m}$ (more detail see Chung, D.H, 2008). The maximum depth is approximately $32 \mathrm{~m}$ and is divided into 32 vertical layers with the regular thickness $\Delta z=1 \mathrm{~m}$. The Ba Lat Mouth is more than $1000 \mathrm{~m}$ wide and is a part of the computation area as an internal open boundary, of which the measured water level is used as boundary condition. The water levels at the other open boundaries are created by MODELGRID based on the formula of the harmonic constants. The computed results of FSUM model are presented in Figures 23-25. They confirm a very good fitness between water levels by FSUM and the ones by the formula as mentioned.

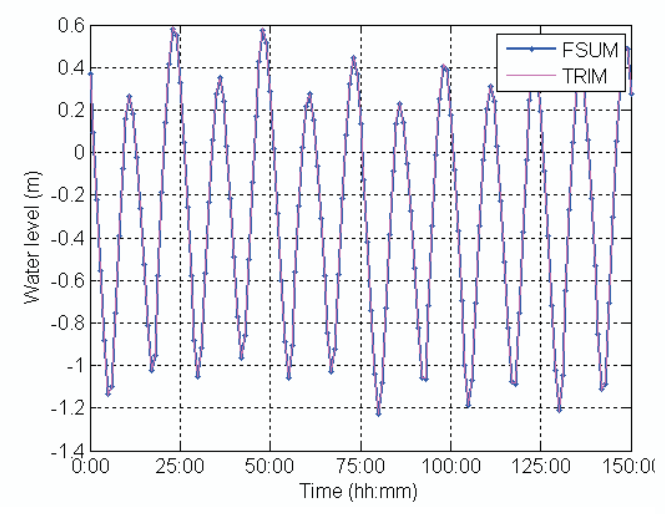

Fig. 6. Water levels versus time at the position 3

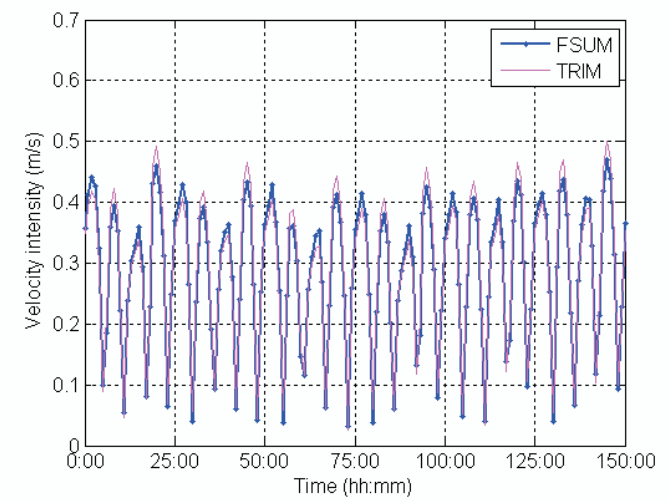

Fig. 7. Velocity near bottom versus time at the position 1

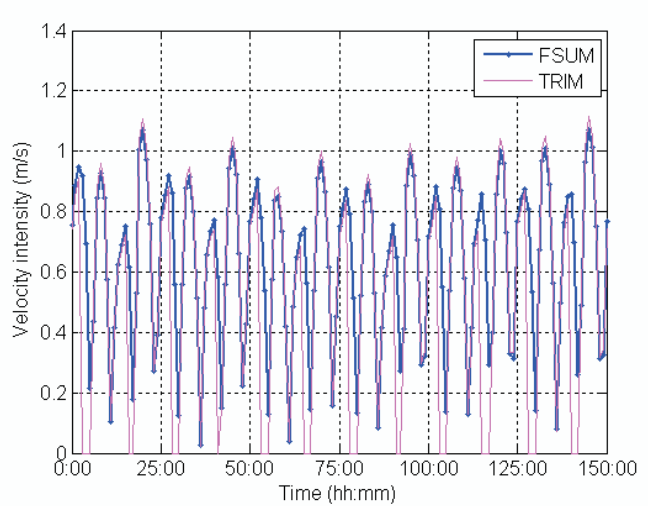

Fig. 8. Velocity at $0.5 \mathrm{~m}$ below MSL versus time at the position 1

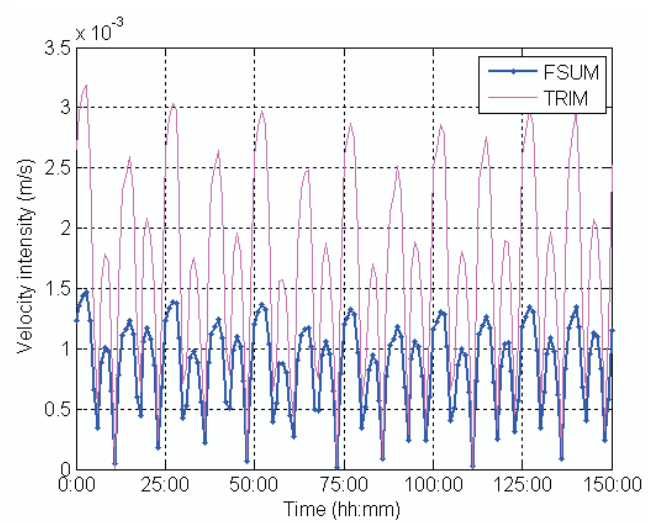

Fig. 9. Velocity near bottom versus time at the position 2 


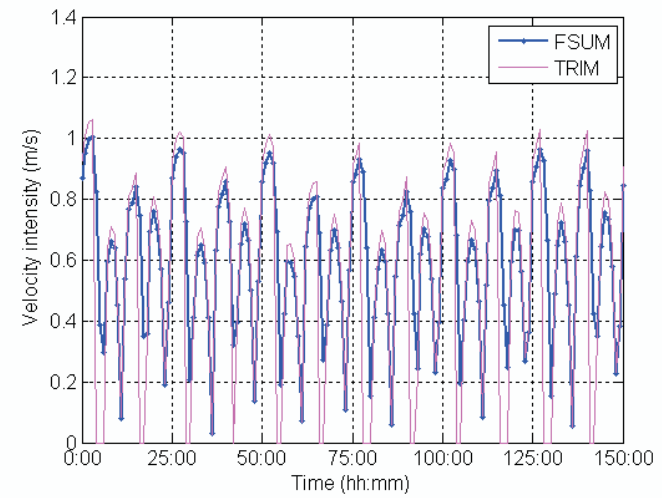

Fig. 10. Velocity at $0.5 \mathrm{~m}$ below MSL versus time at the position 2

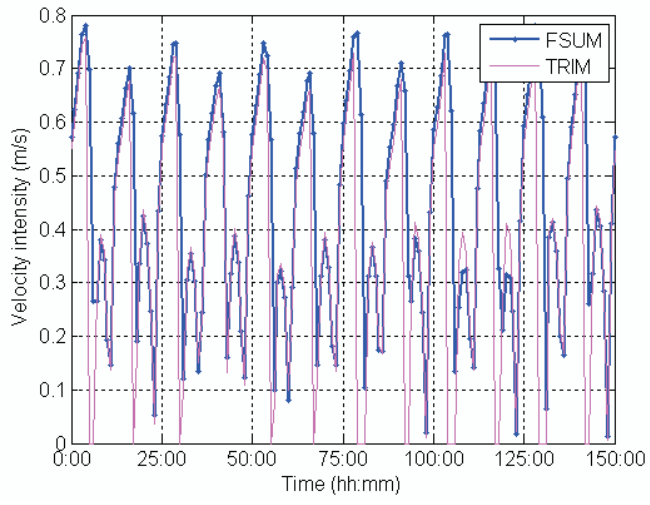

Fig. 12. Velocity at $0.5 \mathrm{~m}$ below MSL versus time at the position 3

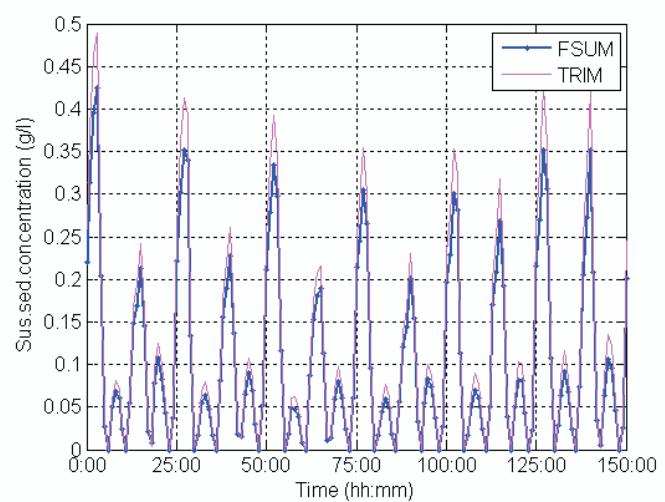

Fig. 14. Sand concentration at $0.5 \mathrm{~m}$ below MSL versus time at the position 2

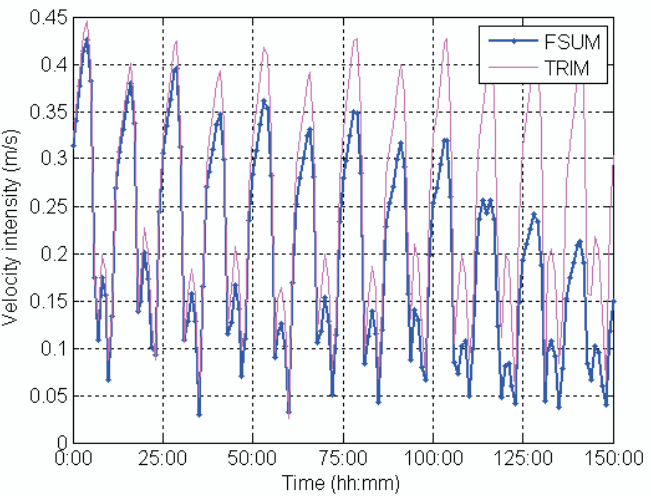

Fig. 11. Velocity near bottom versus time at the position 3

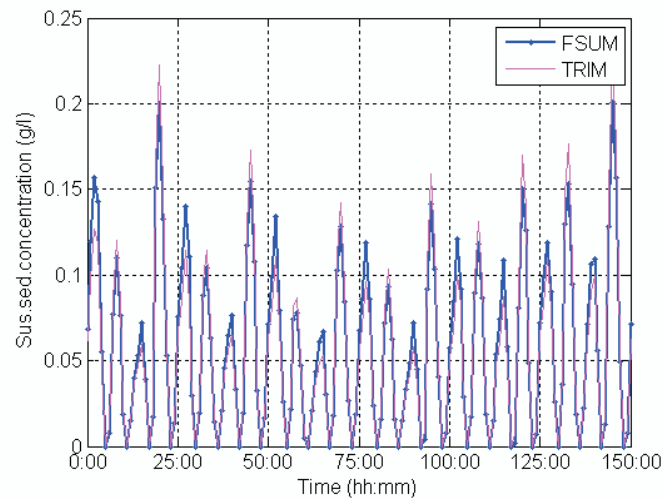

Fig. 13. Sand concentration at $0.5 \mathrm{~m}$ below MSL versus time at the position 1

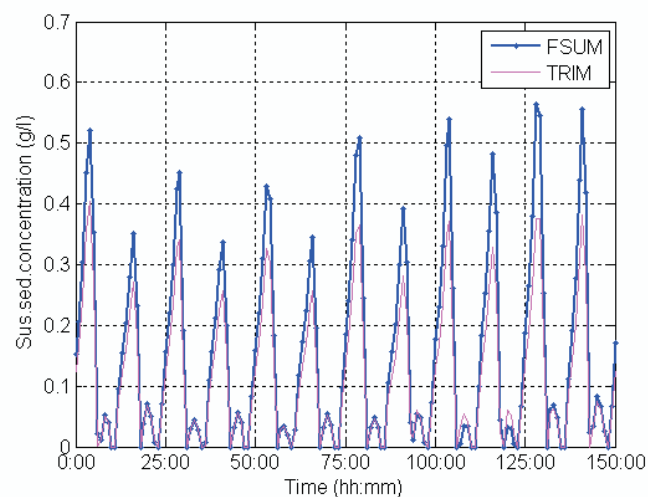

Fig. 15. Sand concentration at $0.5 \mathrm{~m}$ below MSL versus time at the position 3 




Fig. 16. Total sand transport rate versus time at the position 1

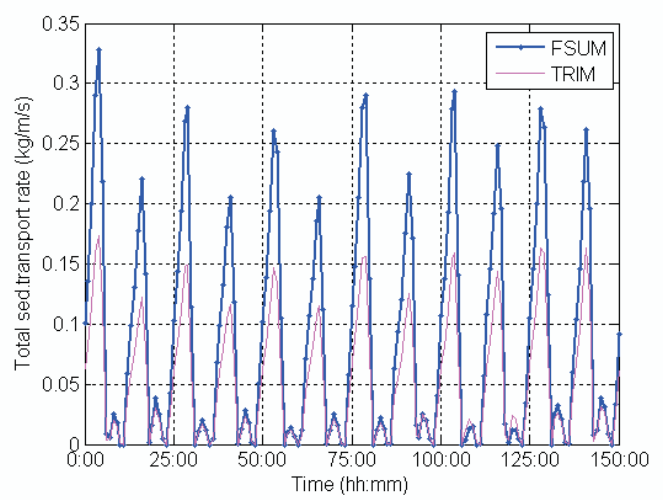

Fig. 18. Total sand transport rate versus time at the position 3

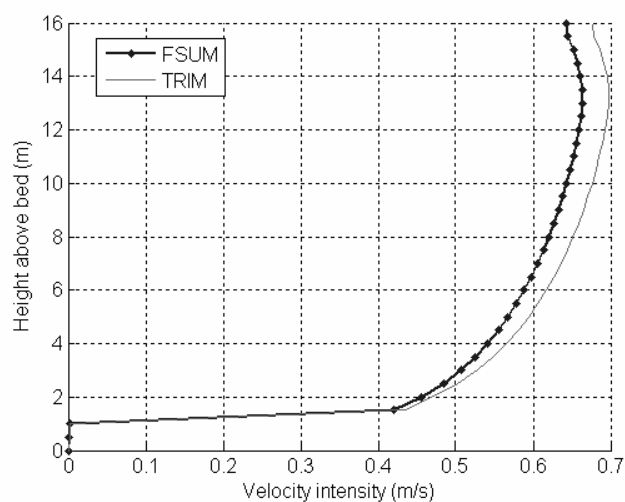

Fig. 20. Velocity profile at the position 2 $(\mathrm{t}=80 \mathrm{hrs})$

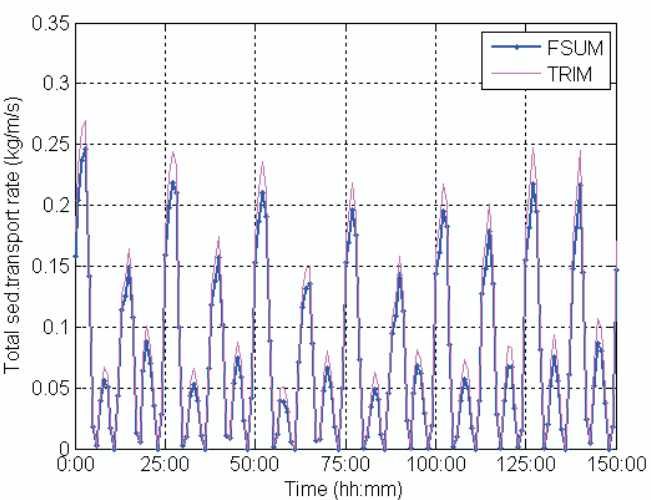

Fig. 17. Total sand transport rate versus time at the position 2

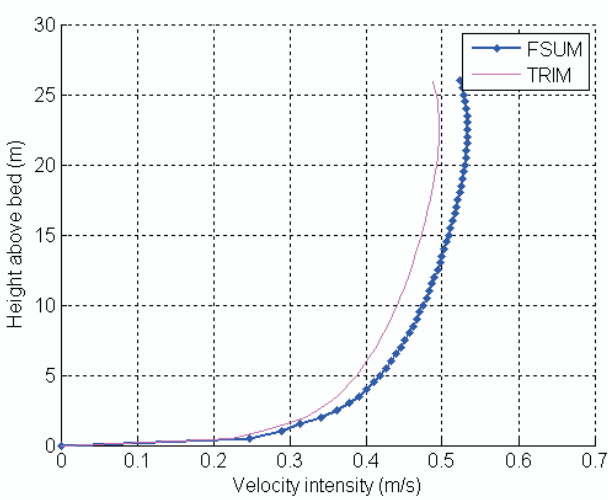

Fig. 19. Velocity profile at the position 1 $(\mathrm{t}=80 \mathrm{hrs})$

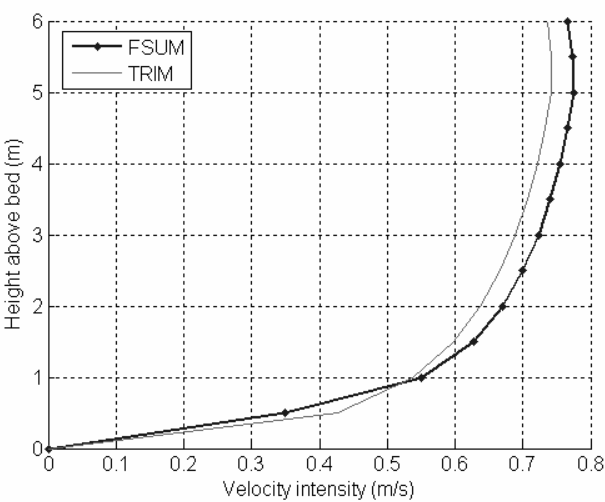

Fig. 21. Velocity profile at the position 3 $(\mathrm{t}=80 \mathrm{hrs})$ 


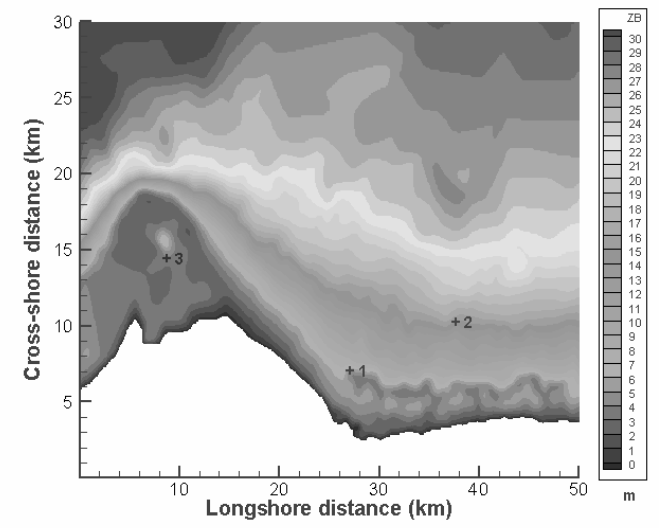

Fig. 22. Bathymetry of Balat coastal zone

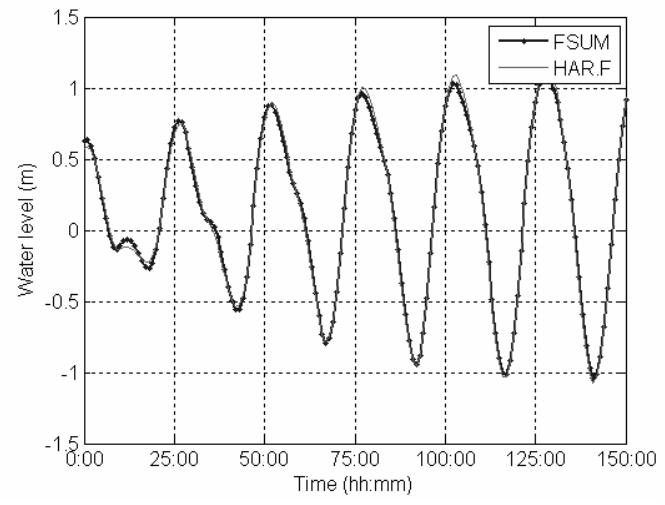

Fig. 24. Water levels versus time at the position 2

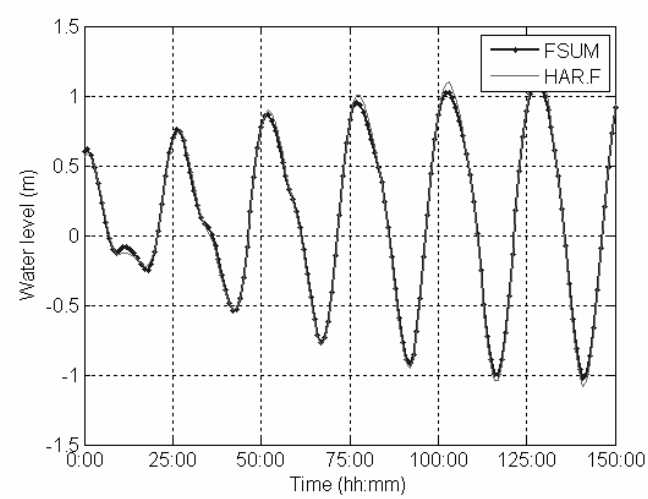

Fig. 23. Water levels versus time at the position 1

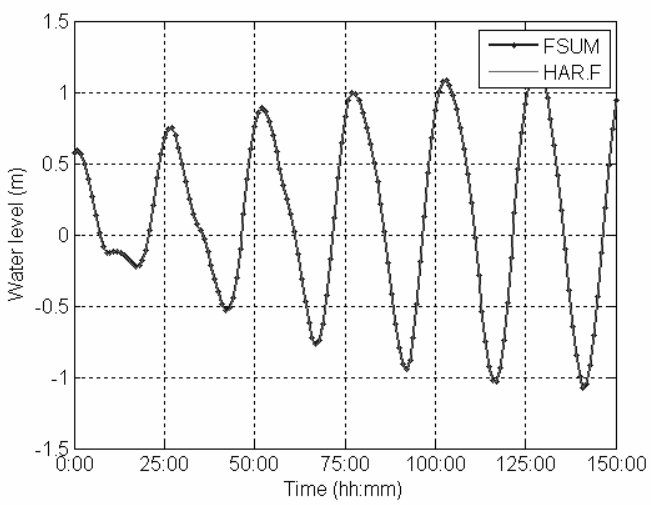

Fig. 25. Water levels versus time at the position 3

\section{CONCLUSIONS}

From the computed results of three cases it is observed that the predicted water level is a hydrodynamics variable with higher accuracy than velocity. The adjustment of water level by the model can be carried out by changing the value of Manning's roughness coefficient. The higher value of roughness coefficient has, the lower water level is. However, the water level at a position with sudden change of the bathymetry is difficult to simulate well and therefore will be less accurate. The transport of substances due to initial distributions or open boundary conditions can be well simulated by the model. In general it shows that FSUM model is completely able to use in practice. 


\section{REFERENCES}

[1] V. Casulli, and G. S. Stelling, Numerical simulation of 3D quasi-hydrostatic, free-surface flows, Journal of Hydraulic Engineering 124 (1998) 678-698.

[2] T. J. Chesher, et al., A morphodynamic coastal area model, HR Wallingford,Report SR 337, 1993.

[3] Dang Huu Chung, Numerical simulation of sediment transport from Ba Lat Mouth and the process of coastal morphology, J. Geophys. Eng. 5 (2008) (1) 46-53

[4] Dang Huu Chung, Effects of temperature and salinity on the suspended sand transport, International Journal of Numerical Methods for Heat \& Fluid Flow 17 (2007) (5) 512-521.

[5] Dang Huu Chung and D. Eppel, Effects of some parameters on numerical simulation of coastal bed morphology, International Journal of Numerical Methods for Heat $\& 3$ Fluid Flow 18 (2008) (5) 575-592

[6] Dang Huu Chung and D. Eppel, Sensitivity of bed morphology within a 3-D numerical model, Proc. 3rd IAHR Symposium on River, Coastal and Estuarine Morphodynamics, Barcelona, 2003, vol.1, pp. $678-683$

[7] Dang Huu Chung and L. C. Van Rijn, Diffusion approach for suspended sand transport under waves, Journal of Coastal Research 19 (1) (2003) 1-11.

[8] R. Soulsby, Dynamics of marine sands, Thomas Telford Publications, Thomas Telford Services Ltd., London, 1997.

[9] L. C. Van Rijn, Sediment transport: part I: bed load transport; part II: suspended load transport; part III: bed forms and alluvial roughness, J. Hydraul. Div. , Proc. ASCE, 110 (1984) (HY10), pp. 1431-56; (HY11), pp. 1613-41; (HY12), pp. 1733-54.

Received April 29, 2009

\section{MÔ HİNH FSUM VÀ CÁC ỨNG DỤNG}

Trong bài báo này một mô hình 3 chiều (FSUM) về dòng chảy vận tải bùn cát, biến đổi đáy và có trao đổi nhiệt-mặn trong vùng cửa sông, ven biển sẽ được giới thiệu chi tiết. Phương pháp sai phân hữu hạn ẩn dựa trên phương pháp bán Lagrange đã được sử dụng. Phần mềm được xây dựng với ngôn ngữ FORTRAN 90/95. Các dạng điều kiện biên hở cùng với các điểm nguồn bổ sung đã được xử lý tốt bởi mô hình, do đó nó có thể được áp dụng cho mọi miền tính toán có địa hình phức tạp. Phần mềm đã được tính toán kiểm nghiệm và áp dụng cho nhiều trường hợp khác nhau, chứng tỏ khả năng áp dụng trong thực tế. 